\title{
UPAYA MENINGKATKAN HASIL BELAJAR SISWA KELAS VII DENGAN MODEL GUIDE NOTE TAKING DI SMP SAN KARLOS HABI
}

\author{
Mansur $\mathbf{S}^{1^{*}}$, Marselina Paula Purek Loli ${ }^{2}$ \\ ${ }^{1,2}$ Universitas Nusa Nipa Nusa Tenggara Timur, Indoensia \\ "Email: mansursaputr00@gmail.com
}

Received: April $8^{\text {th }}, 2019$. Accepted: June $26^{\text {th }}, 2019$. Published: June $29^{\text {th }}, 2019$

\begin{abstract}
The method of this research is classroom action research (CAR). This research consisted two cycles and each cycles consist of four procedure such as, planning, action, observation, and reflection. This research was done at junior high school of San Karlos Habi and subject of this research were 21 students of eight grade of class B. The objective of this research is to improve the result of students learning of biology subject by using cooperative learning style through guided note taking type of eight grade students at junior high school of San Karlos Habi in blood transfusions material the implemented of cooperative learning style through guided note taking type is teacher explain the material, while the students listen carefully and follow the explanation from their teacher, after that teacher make the group and asked them to discuss and also asked them to fill the blank on their worksheet or handout that had given. Finally the teacher make the evaluation of learning outcomes. The results showed that the application of the guided note taking cooperative learning model could improve the learning outcomes of class VIII students on the subject of the circulatory system in humans with student completeness of $85.7 \%$ and the activity of students in the learning process increased by $81.81 \%$.
\end{abstract}

Keywords: guided note taking, learning outcomes, blood transfuse.

\begin{abstract}
Abstrak
Penelitian ini adalah jenis penelitian tindakan kelas (PTK) dengan dua siklus yang terdiri dari empat tahap di setiap siklusnya yaitu perencanaan, tindakan atau pelaksanaan, observasi dan refleksi. Penelitian ini dilaksanakan di SMP San Karlos Habi dengan subjek penelitian sebanyak 21 orang pada kelas VIII B. Tujuan dari penelitian ini untuk meningkatkan hasil belajar biologi siswa dengan model pembelajaran kooperatif tipe guided note taking di kelas VIII pada pokok bahasan sistem peredaran darah pada manusia di SMP San Karlos Habi. Penelitian ini menggunakan model pembelajaran kooperatif tipe Guided Note Taking. Guru menjelaskan materi sementara siswa memperhatikan penjelasan, selanjutnya guru mengadakan diskusi kelompok disertai dengan pengisian point-point yang dikosongkan pada handout dan diakhiri dengan proses evaluasi hasil belajar. Hasil penelitian menunjukkan bahwa penerapan model pembelajaran kooperatif tipe guided note taking dapat meningkatkan hasil belajar siswa kelas VIII pada pokok bahasan sistem peredaran darah pada manusia dengan ketuntasan siswa sebesar $85,7 \%$ dan keaktifan siswa dalam proses belajar meningkat sebesar $81,81 \%$.
\end{abstract}

Kata Kunci: guided note taking, hasil belajar, sistem peredaran darah.

\section{PENDAHULUAN}

Pendidikan merupakan perubahan sikap dan tingkah laku seseorang atau sekelompok dalam hal mendewasakan manusia melalui upaya pengajaran dan pelatihan. Pendidikan yang baik akan berdampak pada peningkatan kualitas manusianya, pendidikan 
juga merupakan kebutuhan yang sangat penting bagi kehidupan setiap manusia, sehingga akan mudah di temukan masyarakat yang berkompeten di berbagai bidang (Farida, Suherman, \& Zulfikar, 2019; Rodiawati \& Komarudin, 2018). (Hamalik, 2015) mengatakan bahwa pendidikan adalah suatu proses dalam rangka mempengaruhi siswa supaya mampu menyesuaikan diri sebaik mungkin dengan lingkungannya. Hal ini akan membentuk dan mencerdaskan kehidupan bangsa yang memiliki pengetahuan dan keterampilan, kesehatan jasmani dan rohani, kepribadian yang mantap dan mandiri serta bertanggung jawab kemasyarakatan dan berkebangsaan ( Nuryani, 2005; Karyanti \& Komarudin, 2017).

Pendidikan akan berpengaruh pada proses pembelajaran. Keberhasilan pembelajaran tergantung pada proses pembelajaran (Aunurrahman, 2016). Karena belajar merupakan perubahan disposisi atau kemampuan yang dicapai seseorang melalui aktivitas (Suprijono, 2009). Proses belajar akan memperkuat daya ingat siswa. Daya ingat teersebut salah satunya dengan mencatat atau menulis. Mencatat atau menulis merupakan kegiatan yang tidak terpisahkan dari aktivitas belajar siswa. Kegiatan mencatat merupakan aktivitas yang sering dilakukan dalam berbagai jenjang pendidikan. Pembuatan catatan membantu siswa dalam mempelajari informasi secara singkat dan dapat menyimpan informasi untuk ulangan dan dihafal (Trianto, 2007). Hal ini dilakukan untuk membantu mengorganisasikan informasi sehingga informasi itu dapat diproses dan dikaitkan dengan pengetahuan yang telah ada secara lebih efektif.

Berdasarkan hasil observasi yang telah dilakukan di SMP San Karlos Habi menunjukkan bahwa beberapa masalah pokok dalam proses pembelajaran, yaitu siswa kurang konsentrasi dalam mengikuti pelajaran sehingga mengakibatkan perilaku siswa menjadi pasif, tidak mendengarkan, tidak mencatat dan bahkan tidak mengikuti materi yang diberikan oleh guru. Hal ini berdampak pada nilai siswa kelas VIII yang belum mencapai Kriteria Ketuntasan Minimal (KKM) sesuai dengan acuan sekolah yaitu 75\%. Dalam penelitian (Ulya, Irawati, \& Maulana, 2016) mengungkapkan bahwa hasil belajar yang belum menggembirakan di atas antara lain karena model pembelajaran kurang mendorong siswa berinteraksi dengan sesama siswa dalam belajar (Hardiani, Irawati, \& Maulana, 2017; Setiaji \& Suherman, 2019)

Proses pembelajaran untuk mencapai KKM harus menggunakan sebuah model pembelajaran yang menekankan pada partisipasi siswa. Proses pembelajaran di SMP San Karlos Habi saat ini menunjukkan bahwa guru masih mendominasi kegiatan pembelajaran dengan memberikan materi sebanyak-banyaknya sehingga pada proses pembelajaran di kelas siswa menjadi kurang aktif, sibuk sendiri, dan jarang mencatat poin-poin penting yang disampaikan oleh guru sehingga berdampak pada rendahnya hasil belajar.

Berdasarkan pemaparan hasil observasi di atas, maka dibutuhkan salah satu model pembelajaran yang dapat meningkatkan hasil belajar siswa. Salah satu model pembelajaran yang dapat digunakan adalah model pembelajaran kooperatif tipe Guided Note Taking.

Berbagai penelitian terkait Guided Note Taking memberikan hasil bahwa penerapan model pembelajaran guided note taking dapat meningkatkan aktivitas dan prestasi belajar (Narjaikaew, Emarat, \& Cowie, 2009). Senada dengan pendapat tersebut, bahwa penggunaan model pembelajaran Guided Note Taking dapat menunjukkan perbedaan yang signifikan antara kelas kontrol dan kelas eksperimen berdasarkan nilai rata-rata hasil belajarnya (Subroto, 2012)

Berdasarkan hal tersebut, nampak jelas bahwa Guided Note Taking akan memberikan dampak yang positif terhadap belajar siswa. Adapun penelitian ini mempunyai perbedaan dari penelitian sebelumnya, bahwa penelitian ini memfokuskan pada pemberian 
catatan terbimbing (guided note taking) antara lain bahwa siswa akan menghasilkan catatan selama belajar yang lengkap dan akurat. Catatan terbimbing meningkatkan keaktifan siswa dalam menangkap isi dari materi pembelajaran. Siswa akan aktif menanggapi ceramah yang diberikan oleh guru dengan mendengarkan, melihat, memikirkan, dan menulis.

\section{METODE PENELITIAN}

Penelitian ini adalah penelitian tindakan kelas (classroom action research) dengan tujuan untuk memperbaiki kinerjanya sehingga hasil belajar siswa meningkat. Penelitian ini terdiri dari 2 siklus, yang terdiri dari perencanaan, pelaksanaan, observasi, dan refleksi. Objek penelitian ini adalah siswa kelas VIII.B SMP Santu Karlos Habi tahun ajaran 2017/2018 yang berjulmah 21 orang, yang terdiri dari perempuan 13 orang dan laki-laki sebanyak 10 orang.

Teknik atau cara pengumpulan data dalam penelitian ini yaitu sebagai berikut:

a) Observasi selama pembelajaran

Observasi selama pembelajaran dilakukan dengan mengamati aktifitas siswa selama pelajaran.

b) Pemberian test

Teknik ini digunakan untuk mengetahui peningkatan hasil belajar siswa dengan guru memberikan soal dan siswa menjawabnya. Tes dilakukan sebanyak 3 kali selama penelitian yaitu pada saat pre-test, post-test siklus I dan post-tes siklus II untuk mengetahui hasil belajar siswa setelah penerapan metode pembelajaran Guided Note Taking.

Analisis data menggunakan teknik perhitungan hasil belajar individu dan mean. Ukuran lain yang digunakan adalah presentase belajar siswa secara klasikal. Hasil belajar siswa ditentukan berdasarkan hasil tes yang telah dilakukan dengan menggunakan instrumen yang telah dibuat. Hasil belajar individu dikatakan berhasil apabila siswa mendapat nilai 75 yakni sesuai dengan Kriteria Ketuntasan Minimal (KKM). Rumus yang digunakan untuk menentukan hasil belajar individu sebagai berikut:

$$
\text { Nilai }=\frac{\text { Jumlah Skor Perolehan }}{\text { Skor Max }} \times 100
$$

Mean adalah teknik penjelasan kelompok yang didasarkan atas nilai rerata dari kelompok tersebut. Rumus perhitungan mean yang digunakan adalah sebagai berikut:

$$
\bar{x}=\frac{\sum x}{N}
$$

Keterangan

$\bar{x} \quad=$ Mean (rerata)

$\sum x \quad=$ jumlah nilai

$N \quad=$ Jumlah siswa yang mengikuti tes

Nilai tes yang telah didapatkan akan disusun dan penyajian hasil data tes menggunakan teknik presentase. Berikut rumus untuk menentukan presentase kelulusan:

$$
\text { Presentase }=\frac{\text { jumlah lulus } K K M}{\text { jumlah peserta didik }} \times 100
$$




\section{HASIL PENELITIAN DAN PEMBAHASAN} berikut.

Berdasarkan analisis data pada siklus I terhadap 21 siswa, diperoleh data sebagari

Tabel 1. Hasil Evaluasi Siklus I

\begin{tabular}{ccccc}
\hline No. & Interval nilai & Persentase & Jumlah siswa & Keterangan \\
\hline 1 & $75-100$ & $38,1 \%$ & 8 orang & Tuntas \\
2 & $0-74$ & $61,9 \%$ & 13 orang & Tidak tuntas \\
\hline
\end{tabular}

Berdasarkan perolehan nilai di atas yang telah dianalisis sesuai dengan KKM 75, maka terdapat 8 orang siswa yang masuk kategori lulus, dan 13 orang yang masuk kategori belum lulus. Berikut ini gambar grafik persentase ketuntasan evaluasi siswa siklus I:

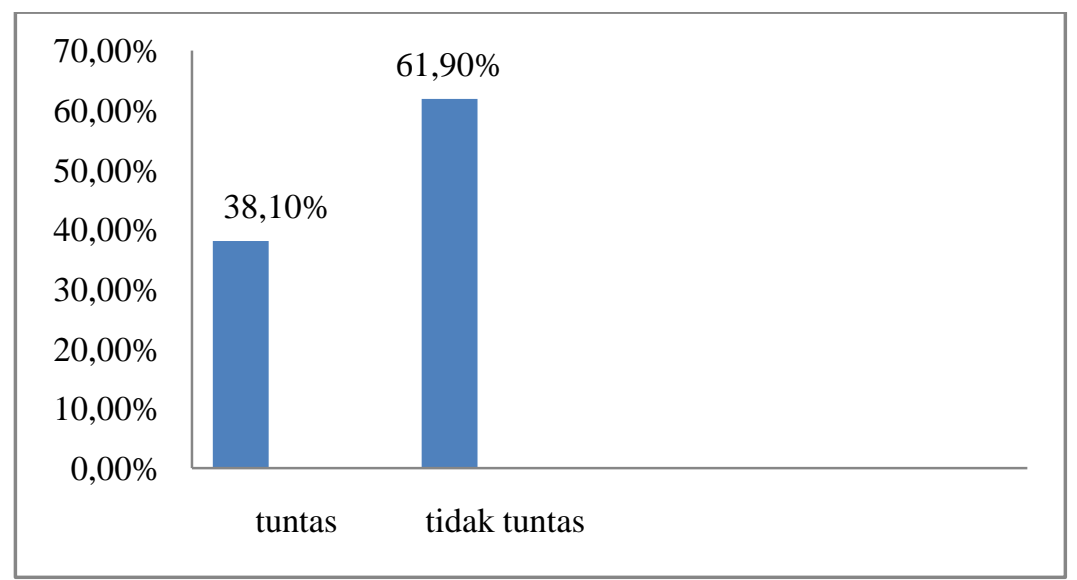

Grafik 1. Hasil Persentase Evaluasi Siklus I

Jumlah siswa yang hadir sebanyak 21 orang, dengan nilai rata-rata posttest siklus I yaitu 66,7. Hasil belajar siswa pada siklus I dengan persentasi siswa yang sudah tuntas sebesar $38,1 \%$ dan siswa yang belum tuntas $61,9 \%$.

\section{Tahap Observasi}

Hasil observasi keaktifan siswa dalam pembelajaran biologi dengan materi sistem peredaran darah pada manusia pada siklus I menggunakan model pembelajaran guided note taking mencapai 54,54\% dengan jumlah skor kriteria belajar 24 dan skor maksimum 44 . Berikut ini disajikan grafik hasil observasi keaktifan siswa pada siklus I.

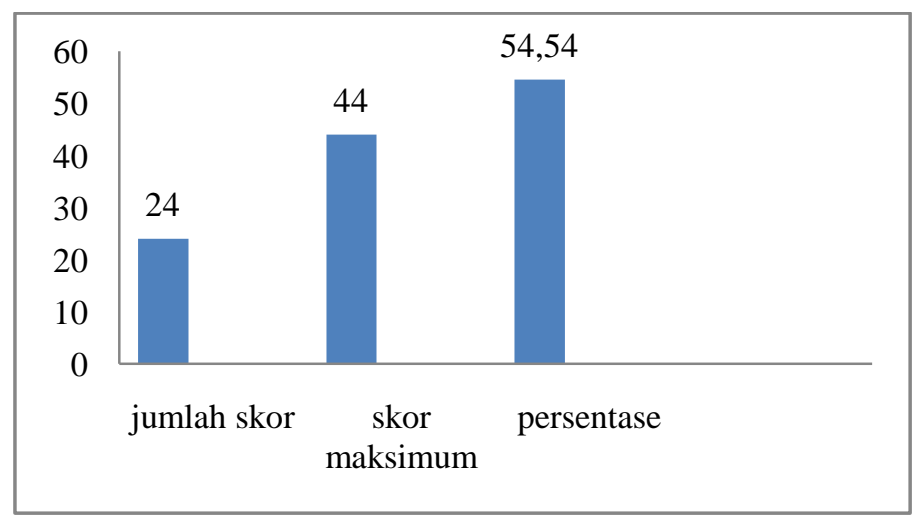

Grafik 2. Hasil Observasi Keaktifan Belajar Siswa Siklus I 
Berdasarkan hasil observasi terhadap pelaksanaan model pembelajaran guided note taking pada siklus I dapat disimpulkan bahwa pembelajaran materi sistem peredaran darah pada manusia belum optimal. Hasil evaluasi menunjukan bahwa pada siklus I belum mengalami peningkatan. Melihat hasil di atas maka peneliti akan melanjutkan pelajaran pada siklus II agar hasil belajar yang dicapai oleh siswa dapat lebih optimal.

Tabel 2. Hasil Evaluasi Siklus II

\begin{tabular}{ccccc}
\hline No. & Interval nilai & persentase & Jumlah siswa & Keterangan \\
\hline 1 & $75-100$ & $85,7 \%$ & 18 orang & Tuntas \\
\hline 2 & $0-74$ & $14,3 \%$ & 3 orang & Tidak Tuntas \\
\hline
\end{tabular}

Berdasarkan perolehan nilai yang telah dianalisis pada siklus II di atas, maka terdapat 18 orang siswa yang masuk kategori lulus, dan 3 orang masuk kategori belum lulus sesuai KKM yaitu 75, dengan nilai rata-rata 80,7. Berikut ini disajikan grafik persentase ketuntasan evaluasi belajar siswa siklus II:

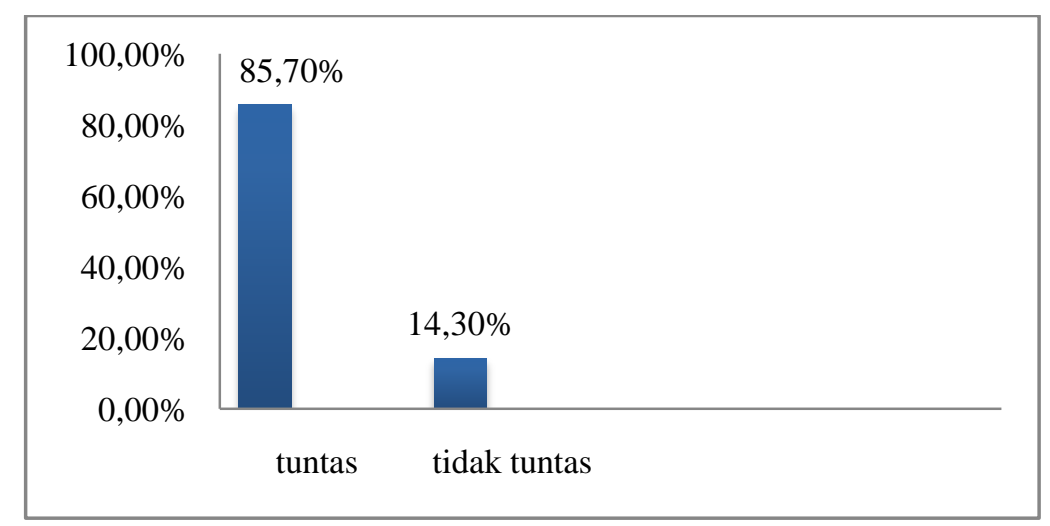

Grafik 3. Ketuntasan Evaluasi Siklus II

Hasil belajar siswa pada siklus II mengalami peningkatan dengan persentasi siswa yang tuntas sebesar $85,7 \%$ dan siswa yang belum tuntas $14,3 \%$.

Hasil observasi keaktifan siswa dalam pembelajaran biologi dengan materi sistem peredaran darah pada manusia pada siklus II dengan menggunakan model pembelajaran guided note taking mencapai $81,81 \%$ dengan jumlah skor kriteria belajar 36 dan skor maksimum 44. Berikut hasilnya disajikan dalam bentuk grafik

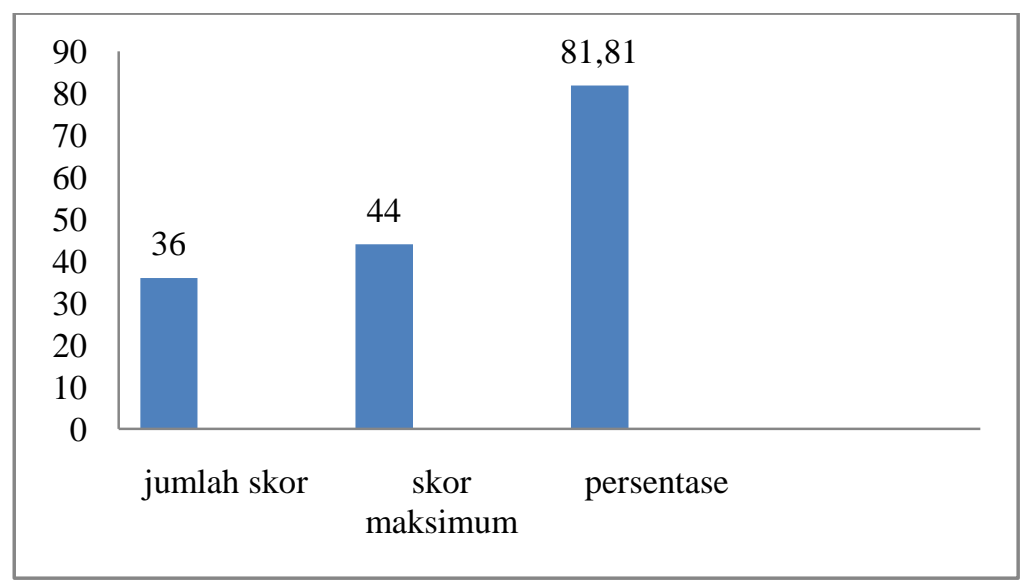

Grafik 4. Hasil Observasi Keaktifan Siswa Siklus II 
Berdasarkan hasil observasi terhadap pelaksanaan model pembelajaran guided note taking pada siklus II dapat disimpulkan bahwa pembelajaran materi sistem peredaran darah pada manusia mengalami peningkatan. Melihat hasil di atas maka peneliti menyimpulkan bahwa, penggunaan model pembelajaran guided note taking pada siklus dua telah berhasil dengan memperoleh persentase kelulusan sebesar 85,7\%.

Penelitian tindakan kelas ini dilaksanakan dalam 2 (dua) siklus dengan tahaptahapnya sesuai dengan prosedur penelitian tindakan kelas (PTK) yang telah ditetapkan yaitu tahap perencanaan, pelaksanaan, observasi, dan refleksi. Proses pembelajaran dalam setiap siklus dilaksanakan sesuai dengan Rencana Pelaksanaan Pembelajaran (RPP) yang telah disusun pada tahap perencanaan. Selama proses pembelajaran berlangsung, dilakukan observasi terhadap aktivitas siswa yang dicatat pada lembar observasi.

Proses pembelajaran pada siklus I sebanyak 2 kali pertemuan yaitu pertemuan pertama pemaparan materi dengan menggunakan model pembelajaran guided note taking. Guru melakukan pembelajaran mengikuti prosedur yang telah dirancang dalam RPP yang sudah disediakan. Pertemuan kedua melakukan posttest. Hasil yang diperoleh pada siklus I yaitu dengan nilai rata-rata 66,7 dan persentase kelulusan $38,1 \%$. Hasil observasi keaktifan belajar siswa mencapai 54,54\%.

Proses pembelajaran pada siklus II sebanyak 2 kali pertemuan dengan menggunakan model pembelajaran yang sama seperti disiklus I. Pertemuan pertama pemaparan materi siklus II oleh guru dengan model pembelajaran guided note taking sesuai dengan RPP yang sudah disediakan. Pertemuan kedua melakukan posttest. Hasil yang dicapai pada posttest siklus dua mengalami peningkatan dengan rata-rata yang dicapai 80,7. Persentase kelulusan siswa pada siklus II sebesar $85,7 \%$. Demikian juga keaktifan siswa dalam proses belajar mengajar juga meningkat yaitu $81,81 \%$.

Sesuai dengan pendapat bahwa model pembelajaran guided note taking dapat meningkatkan keaktifan siswa dalam menangkap isi dari materi yang dipelajari (Kristiani, 2011). Siswa dapat lebih mudah mengidentifikasi informasi penting, karena dalam model pembelajaran guided note taking guru memberikan isyarat dan hubungan agar siswa lebih mampu mendapatkan isi pembelajaran. Selain itu, bahwa penting mengapa model pembelajaran guided note taking dapat meningkatkan prestasi belajar siswa karena dalam model pembelajaran ini siswa dituntut untuk ikut serta dalam pembelajaran (Sundari \& Usada, 2013).

Berdasarkan hasil penelitian di atas dapat dikatakan bahwa ketuntasan belajar siswa dapat dicapai dengan menerapkan model pembelajaran guided note taking. Hal ini tidak terlepas dari semakin meningkatnya aktivitas siswa dalam proses pembelajaran, karena selain memperhatikan materi yang disampaikan oleh guru siswa juga aktif mengisi handout masing-masing, siswa semakin sering bertanya baik kepada guru maupun pada temannya, siswa berani tampil ke depan kelas untuk membacakan handout yang telah diisi.

Jadi penerapan model pembelajaran tipe guided note taking pada materi sistem peredaran darah pada manusia sangat tepat, hal ini terbukti pada pelaksanaan tiap tindakannya siswa bertambah aktif dan semangat. Peneliti selalu mengawasi dan membimbing kegiatan siswa selama pembelajaran berlangsung dan membantu siswa bila ada yang kurang jelas dan belum dipahami sehingga siswa benar-benar memahami materi. 


\section{SIMPULAN DAN SARAN}

Penerapan model pembelajaran kooperatif tipe guided note taking dapat meningkatkan hasil belajar siswa kelas VIII pada pokok bahasan sistem peredaran darah pada manusia dengan ketuntasan siswa sebesar $85,7 \%$ dan keaktifan siswa dalam proses belajar meningkat sebesar $81,81 \%$.

Saran yang diajukan dari penelitian selanjutnya, hendaknya penelitian ini dapat dikembangkan kembali dengan memadukan model lain dan materi lain, sehingga akan dapat meningkatkan prestasi belajar siswa.

\section{DAFTAR PUSTAKA}

Aunurrahman. (2016). Belajara dan Pembelajaran. Bandung: Alfabeta.

Farida, F., Suherman, S., \& Zulfikar, S. (2019). Peningkatan Kemampuan Pemahaman Konsep Himpunan Melalui Pembelajaran Matematika dengan Media Articulate Studio'13. JSHP (Jurnal Sosial Humaniora Dan Pendidikan), 3(1), 20-28.

Hamalik, O. (2015). Kurikulum dan Pembelajaran. Jakarta: Bumi Aksara.

Hardiani, D., Irawati, R., \& Maulana, M. (2017). Penerapan Pendekatan Kontekstual Berbasis Etnografi Majalaya Untuk Meningkatkan Kemampuan Pemecahan Masalah Matematis Siswa Pada Materi Penjumlahan Dan Pengurangan Bilangan Bulat. Jurnal Pena Ilmiah, 2(1), 981-990.

Karyanti, K., \& Komarudin, K. (2017). Pengaruh Model Pembelajaran Kumon Terhadap Pemahaman Matematis Ditinjau Dari Gaya Kognitif Peserta Didik Pada Mata Pelajaran Matematika Kelas VIII SMP Negeri Satu Atap 4 Pesawaran. Prosiding Seminar Nasional Matematika Dan Pendidikan Matematika, 1, 89-94.

Kristiani, L. (2011). Penerapan model guided note taking untuk meningkatkan aktivitas dan hasil belajar IPS siswa kelas IVB SDN Tanjungrejo 5 Malang. Penerapan Model Guided Note Taking Untuk Meningkatkan Aktivitas Dan Hasil Belajar IPS Siswa Kelas IVB SDN Tanjungrejo 5 Malang/Lita Kristiani.

Narjaikaew, P., Emarat, N., \& Cowie, B. (2009). The effect of guided note taking during lectures on Thai university students' understanding of electromagnetism. Research in Science \& Technological Education, 27(1), 75-94.

Nuryani. (2005). Strategi Belajar Mengajar Biologi. Malang: Universitas Negeri Malang.

Rodiawati, H., \& Komarudin, K. (2018). Pengembangan E-Learning Melalui Modul Interaktif Berbasis Learning Content Development System. Jurnal Tatsqif, 16(2), $172-185$.

Setiaji, F., \& Suherman, S. (2019). Analisis Kemampuan Komunikasi Matematis: Dampak Model Pembelajaran Discovery Learning Terintegrasi Learning Start With A Question. Desimal: Jurnal Matematika, 2(1), 33-42.

Subroto, T. (2012). Model Pembelajaran Guided Note Taking Berbantuan Media ChemoEdutainment pada Materi Pokok Koloid. Jurnal Pendidikan IPA Indonesia, 1(1). 
Sundari, E., \& Usada, M. (2013). Penggunaan Metode Guided Note Taking untuk Meningkatkan Hasil Belajar IPS Materi Masalah Sosial. Didaktika Dwija Indria, $1(6)$.

Suprijono. (2009). Cooperative Learning. Yogyakarta: Pustaka Belajar.

Trianto. (2007). Model-Model Pembelajaran Inovatif Berorientasi Konstruktivistik. Jakarta: Perstasi Pustaka. 